\title{
Erratum to: The nature and level of learner-learner interaction in a chemistry massive open online course (MOOC)
}

\author{
Andrew A. Tawfik ${ }^{1}$ - Todd D. Reeves ${ }^{2}$. \\ Amy E. Stich ${ }^{3}$ - Anila Gill ${ }^{4}$ - Chenda Hong ${ }^{4}$. \\ Joseph McDade ${ }^{5}$ - Venkata Sai Pillutla ${ }^{5}$. \\ Xiaoshu Zhou ${ }^{4} \cdot$ Philippe J. Giabbanelli $^{5}$ \\ Published online: 6 April 2017 \\ (c) Springer Science+Business Media New York 2017
}

\section{Erratum to: J Comput High Educ \\ DOI 10.1007/s12528-017-9135-3}

The original version of this article unfortunately contained a mistake in the title. The title should be:

The online version of the original article can be found under doi:10.1007/s12528-017-9135-3.

Andrew A. Tawfik

aatawfik@gmail.com

Todd D. Reeves

treeves@niu.edu

Amy E. Stich

astich@niu.edu

Anila Gill

agill5@niu.edu

Joseph McDade

jmcdade@niu.edu

Venkata Sai Pillutla

vpillutla1@niu.edu

Xiaoshu Zhou

xzhou@niu.edu

Philippe J. Giabbanelli

pgiabbanelli@niu.edu

1 Educational Technology, Research and Assessment, Northern Illinois University, 231 N. Annie Glidden Rd, Gabel Hall (Office 101G), Dekalb, IL 60115, USA 
The nature and level of learner-learner interaction in a chemistry massive open online course (MOOC) instead of The nature and level of learner-learner in a chemistry massive open online course (MOOC).

The title is corrected with this erratum. The original article was also corrected.

2 Educational Technology, Research and Assessment, Northern Illinois University, 231 N. Annie Glidden Rd, Gabel Hall 204A, Dekalb, IL 60115, USA

3 Department of Leadership, Educational Psychology and Foundations, Northern Illinois University, 231 N. Annie Glidden Rd, Graham Hall (GA 204A), Dekalb, IL 60115, USA

4 Educational Technology, Research and Assessment, Northern Illinois University, 231 N. Annie Glidden Rd, Dekalb, IL 60115, USA

5 Computer Science, Northern Illinois University, 231 N. Annie Glidden Rd, Dekalb, IL 60115, USA 